Journal of Current and Advance Medical Research

January 2019, Vol. 6, No. 1, pp. 53-58

http://www.banglajol.info/index.php/JCAMR

ISSN (Print) 2313-447X

ISSN (Online) 2413-323X

NLM Catalog ID 101673828

DOI: https://doi.org/10.3329/jcamr.v6i1.40786

ORIGINAL ARTICLE OPEN ACCESS

\title{
Status and Patients Satisfaction Attended at Emergency Department of a Tertiary Level Hospital in Dhaka City
}

\author{
Khursheda Akhtar ${ }^{1}$, Md. Mamun Or Rashid ${ }^{2}$, Khodeza Akhtar $^{3}$, Ayesha Siddika $^{4}$, \\ Syeda Subrina Siddika ${ }^{5}$
}

${ }^{1}$ Lecturer, Department of Community Medicine, Mugda Medical College, Dhaka, Bangladesh; ${ }^{2}$ Assistant Professor, Department of Orthopedics, Col. Malek Medical College, Manikganj, Bangladesh; ${ }^{3}$ Assistant Professor, Conservative Dentistry, Dental Unit, Chittagong Medical College, Chittagong, Bangladesh; ${ }^{4}$ Lecturer, Department of Community Medicine, Mugda Medical College, Dhaka, Bangladesh; ${ }^{5}$ Lecturer, Department of Community Medicine, Mugda Medical College, Dhaka, Bangladesh

[Received on: 2 July 2018; Reviewed on: 12 July 2018; Accepted on: 1 August 2018; Published on: 1 January 2019]

\section{Abstract}

Background: Emergency department is one of the most important parts of a hospital which is the point of major public health interest. Objective: The purpose of the present study was to find out the existing facilities of emergency department, to assess the satisfaction of patients and health care providers on emergency services. Method: This cross-sectional study was carried out at emergency department of Mugda Medical College, Dhaka, Bangladesh from January 2017 to June 2017 for a period of six (06) months. Research instruments were semi structured questionnaire. Existing facilities at emergency department were assessed by check list which was adopted from Table of Equipment (TOE) by Directorate General of Health Service (DGHS) and satisfaction level was categorized as good and bad. Face to face interview was taken from emergency patients and health care providers attending in emergency unit. Result: A total of 75 samples of respondents were selected purposively. Most of the respondents (30.0\%) were in 26 to 35 years age group. According to their education level, 24(48.0\%) were illiterate. Most of the respondents $(76.0 \%)$ were attended to emergency unit by walking; however $48(96.0 \%)$ respondents attended by health care providers immediately. Half of the patients $(50.0 \%)$ buy drugs from local dispensary and investigation in hospital was also done by half of the patients. After reaching at emergency, maximum patients $25(50.0 \%$ ) waited for 1 to 5 minutes for receiving medical attention and mean waiting time was 10.14 minutes. Overall satisfactory level at emergency unit was good $23(46.0 \%)$ and bad 27(54.0\%) $(\mathrm{p}<0.0001)$. Conclusion: Numbers of potential barriers influence the patients' satisfaction. Periodic patient satisfaction survey should be institutionalized to provide feedback for continuous quality improvement. [Journal of Current and Advance Medical Research 2019;6(1):53-58]

Keywords: Emergency unit; satisfactory level; tertiary level hospital

Correspondence: Dr. Khursheda Akhtar, Lecturer, Department of Community Medicine, Mugda Medical College, Dhaka, Bangladesh; Email: khurshedaakhter11588@gmail.com; Cell no.: +8801714712174

Cite this article as: Akhtar K, Rashid MMO, Akhtar K, Siddika A, Siddika SS. Status and Patients Satisfaction Attended at Emergency Department of a Tertiary Level Hospital in Dhaka City. J Curr Adv Med Res 2019;6(1):53-58

Funding: This study has been performed without any funding from outside else.

Conflict of Interest: There was no conflict of interest to any of the authors.

Contributions to authors: Akhtar K, Rashid MMO involved in protocol preparation, data collection - Akhtar K, Siddika A, Siddika SS. statistical analysis- Akhtar K; Akhtar K, Siddika A, Siddika SS had involved in manuscript writing \& revision of the manuscript.

Copyright: (2019. Akhtar et al. Published by Journal of Current and Advance Medical Research. This article is published under the Creative Commons CC BY-NC License (https://creativecommons.org/licenses/by-nc/4.0/). This license permits use, distribution and reproduction in any medium, provided the original work is properly cited, and is not used for commercial purposes. 


\section{Introduction}

Health as a fundamental right, is gaining popularity in the past few decades and it has become a social goal $^{1}$. Provision of services in line with the wishes and needs of patients is central to a humane health care system ${ }^{2}$. Health care scenario is fast changing all over the world ${ }^{1}$. The health care system consisting of doctors, paramedic staff, hospital equipments, makes up the medical determinants of the health care system, whereas, non-medical determinants comprise of physical infrastructure, ambiance, availability of spacious room and hygiene qualities ${ }^{3}$. One of the WHO's six building blocks of health systems is the delivery of health services that are effective, safe and of good quality for those who need them. Hospital is an integral part of our society, function of which is to provide complete health care of total population. Emergency department is one of the most important part of a hospital which is the point of major public health interest. The reputation of a hospital rests to a large extent on the service of emergency department.

Emergency department is primarily meant for immediate medical attention and resuscitation of serious ill patients. At a hospital level, providing a quality service is usually challenged by burdensome patients' flow and the urgent nature of care in the emergency department (ED) further suppresses the effort. And hence, assessing the patients' satisfaction as a quality of care indicator is required to monitor the non-technical aspects of quality of care in such settings. Measuring client or patient satisfaction has become an integral part of hospital/clinic management strategies across the globe $^{4}$. Prompt service is perceived as very important for patients, probably the primary factor determining their judgment the patients' satisfaction $^{5}$. The measurement of patient satisfaction is an important tool for research, administration, and planning. Patient is one who decides the quality, who accepts the services, who makes others to accept it, who gives correct feedback about the performance of hospital and makes the programme of total quality management successful ${ }^{1}$. Patient satisfaction has been defined as the degree of congruency between a patient's expectations of ideal care and his /her perception of the real care (s) he receives. It is a multidimensional aspect, represents a vital key marker for the quality of health care delivery and this is an internationally accepted factor which needs to be studied repeatedly for smooth functioning of the health care systems ${ }^{6}$. Bangladesh has a three-tier health system: primary, secondary and tertiary level health care.
The primary level health care is composed of health post, health center and primary hospital.

A general hospital constitutes the secondary level health care. Meanwhile, specialized hospital makes the tertiary level and expected to serve up to five million people ${ }^{4}$. In accord with practices in all government health facilities in Bangladesh, people coming to the health services registered and waited their turn for consultation. The same health worker provided services to people, irrespective of the condition they presented with. On average, 40 patients used the facilities daily, with the average waiting time at those facilities being $30+2.5 \mathrm{~min}$. The median waiting time was $19 \mathrm{~min}^{7}$. And this study was conducted at a facility grouped under tertiary level care. It is well known that accident and sudden attack of illness cause loss of life and disability which poses huge economic burden to the family, society, and to the country. Effective efficient and prompt service management can prevent death and disability.

This study is designed to explore out the information regarding management of emergency service in a tertiary level hospital. This study finding will help the managers and health care providers to take measures to improve the management of emergency services in tertiary level hospital of our country. The objectives of the study were to find out the existing facilities of emergency department, to assess the satisfaction of patients and health care providers on emergency services.

\section{Methodology}

This cross-sectional study was carried out at emergency department of Mugda Medical College, Dhaka, Bangladesh which was a tertiary level hospital. The duration of study was from January 2017 to June 2017 for a period of six (6) months. Respondents were selected purposively. Patients who were received emergency services and health care providers (HCP) who gave services to emergency patients were selected as study population. Ethical clearance was taken from ethical committee of Mugda Medical College. Respondents at emergency unit fulfilling the selection criteria were enrolled. Research instruments were semi structured questionnaire and check list. Existing facilities at emergency department were assessed by check list which was adopted from table of equipment (TOE) by Directorate General of Health Services (DGHS) under Ministry of Health and Family Welfare (MOHFW), Bangladesh ${ }^{8}$. The questionnaire 
included socio-demographic questions of patients, questionnaire related to satisfactory level of patients and HCP. Perspectives of the study were explained to the respondents and informed consent was taken from each respondent. Patients who were conscious, not seriously ill and gave informed consents above 16 years old were included in this study and who did not comply with the informed written consent was excluded from the study. Face to face interview was taken from emergency patients and health care providers attending in emergency unit. Interview was taken to 40 to 45 minutes in length. Satisfaction level was categorized as good and bad. Operational definition of emergency unit, emergency patients and waiting time were given below: Satisfaction was the act of fulfilling a need desire or appetite or feeling gained from such fulfillment ${ }^{9}$. Tertiary level hospital was a hospital that which was provided tertiary health care from specialists in a large hospital after referral from primary care and secondary care ${ }^{9}$. Emergency unit was a part of hospital which was signified the facilities and services provided primarily for the management of patients coming to the hospital in a critical condition for urgent immediate treatment. Emergency patients was the place where patients attended in emergency department after having disease or injury need urgent medical or surgical intervention. Measurement of emergency services was the managerial aspects of services rendered in the emergency unit like available facilities, availability for health personnel, waiting time for receiving service, patients and health care providers' satisfaction regarding emergency services and emergency referral rate etc. Waiting time was the time that had to be spent by respondents before getting desired services.

Statistical analysis: Statistical analyses of the data were performed using the Statistical Package for the Social Sciences (SPSS) for Windows, version 23.0 (SPSS Inc.; Chicago, IL, USA). Descriptive statistics like frequency distribution, mean, median, mode, range, standard deviation etc. were calculated by SPSS program. Association was seen between waiting time and satisfactory level by $t$ test at $p<0.05$ level of significance.

\section{Results}

This cross-sectional study was done at emergency unit of Mugda Medical College with 75 respondents where 50 were patients and 25 were health care providers According to the checklist physical facilities were available but there was a lack of health personnel and materials and equipment.
According to the requirements of table of equipments (TOE) ${ }^{8}$ for 500 beds hospital there was totally absent of stat lab, IPD and mortuary. Pulse Oximeter, DC shock, diathermy, endotracheal tube was absent at emergency unit. There was lack of suture materials also.

Table 1: Socio-demographic variable of respondents $(\mathbf{n}=\mathbf{5 0})$

\begin{tabular}{|c|c|c|}
\hline Variables & Frequency & Percent \\
\hline \multicolumn{3}{|l|}{ Age Group } \\
\hline - 16 to 25 Years & 12 & 24.0 \\
\hline - 26 to 35 Years & 15 & 30.0 \\
\hline - 36 to 45 Years & 10 & 20.0 \\
\hline - More than 45 Years & 13 & 26.0 \\
\hline Mean \pm SD(Years) & \multicolumn{2}{|c|}{$38.28 \pm 15.218$} \\
\hline \multicolumn{3}{|l|}{ Sex } \\
\hline - Male & 26 & 52.0 \\
\hline - $\quad$ Female & 24 & 48.0 \\
\hline \multicolumn{3}{|l|}{ Education } \\
\hline - Illiterate \& sign only & 24 & 48.0 \\
\hline - Primary \& secondary & 14 & 28.0 \\
\hline $\begin{array}{l}\text { - higher secondary \& } \\
\text { above }\end{array}$ & 12 & 24.0 \\
\hline \multicolumn{3}{|l|}{ Occupation } \\
\hline - Housewife & 17 & 34.0 \\
\hline - $\quad$ Service & 15 & 30.0 \\
\hline $\begin{array}{l}\text { - } \begin{array}{l}\text { Businessman \& } \\
\text { others }\end{array} \\
\end{array}$ & 18 & 36.0 \\
\hline \multicolumn{3}{|l|}{ Religion } \\
\hline - Muslim & 48 & 96.0 \\
\hline - $\quad$ Hindu & 2 & 4.0 \\
\hline \multicolumn{3}{|l|}{ Marital status } \\
\hline - $\quad$ Married & 33 & 66.0 \\
\hline - Unmarried & 11 & 22.0 \\
\hline - $\quad$ Divorced \& widow & 6 & 12.0 \\
\hline \multicolumn{3}{|l|}{ Family income } \\
\hline - $5000-9000 \mathrm{tk}$ & 6 & 12.0 \\
\hline - $10000-15000 \mathrm{tk}$ & 26 & 52.0 \\
\hline $\begin{array}{l}\text { - } 16000-20000 \mathrm{tk} \& \\
\text { more }\end{array}$ & 18 & 36.0 \\
\hline Mean \pm SD & $16240.00 \pm 71$ & .425 \\
\hline
\end{tabular}

Most of the respondents 15(30.0\%) was in 26-35 age group. Male was 26(52.0\%) and female were 24(48.0\%). According to their education level, $24(48.0 \%)$ were illiterate and can sign only. Most of the respondents $17(34.0 \%)$ were housewives. Among them maximum 48(96.0\%) were Muslim. $33(66.0 \%)$ were married. Maximum respondents $26(52.0 \%)$ were in $10000-15000$ tk income group (Table 1). 


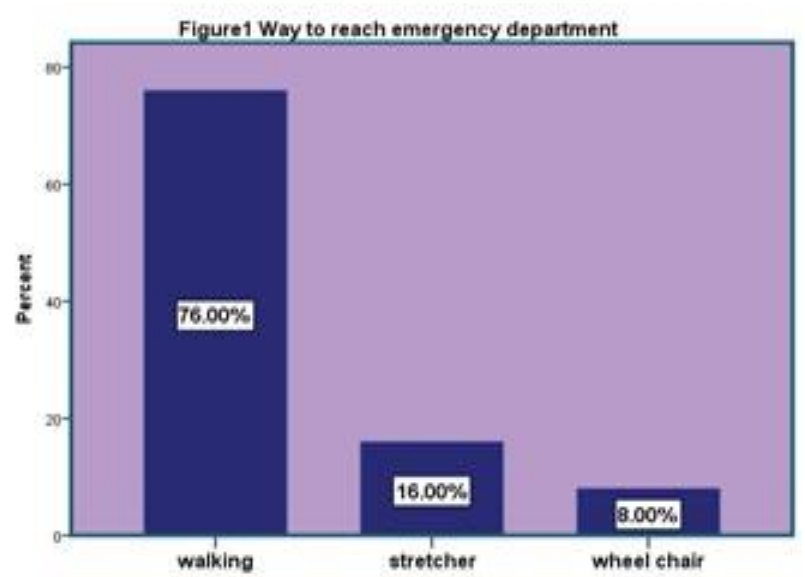

Figure1 shows that maximum respondents $38(76 \%)$ were attended to emergency unit by walking, $8(16 \%)$ respondents were through stretcher and 4 $(8 \%)$ were by wheel chair.

Table 2: Satisfactory level of the patients on emergency unit $(n=50)$

\begin{tabular}{|c|c|c|}
\hline Variables & $\begin{array}{l}\text { Frequenc } \\
\mathbf{y}\end{array}$ & Percent \\
\hline \multicolumn{3}{|c|}{ Display board seen by respondents } \\
\hline - Yes & 43 & 86.0 \\
\hline - $\quad$ No & 7 & 14.0 \\
\hline \multicolumn{3}{|c|}{ Attended by service provider immediately } \\
\hline - Yes & 48 & 96.0 \\
\hline - $\mathrm{No}$ & 2 & 4.0 \\
\hline \multicolumn{3}{|c|}{ Get drugs prescribed by doctors } \\
\hline - Yes & 29 & 58.0 \\
\hline - $\quad$ No & 21 & 42.0 \\
\hline \multicolumn{3}{|c|}{ Get full course of drugs } \\
\hline - $\quad$ Yes & 10 & 20.0 \\
\hline - $\mathrm{No}$ & 40 & 80.0 \\
\hline \multicolumn{3}{|c|}{ Buy any drugs } \\
\hline - Yes & 25 & 50.0 \\
\hline - $\quad$ No & 25 & 50.0 \\
\hline \multicolumn{3}{|c|}{ Investigation done by respondents } \\
\hline - Yes & 25 & 50.0 \\
\hline - $\quad$ No & 25 & 50.0 \\
\hline \multicolumn{3}{|c|}{ Waiting time of respondents (minutes) } \\
\hline - $1-5$ & 25 & 50.0 \\
\hline - $10-15$ & 19 & 38.0 \\
\hline - $20-30$ & 6 & 12.0 \\
\hline \multicolumn{3}{|c|}{$\begin{array}{l}\text { Max-30 minute, Min-3 minute, Mean } 10.14, \\
\text { SD-7.785 }\end{array}$} \\
\hline \multicolumn{3}{|c|}{$\begin{array}{l}\text { Satisfaction on reception facilities, treatment } \\
\text { facilities, service of doctors and service of } \\
\text { HCP at emergency unit }\end{array}$} \\
\hline - $\quad$ Good & 44 & 88.0 \\
\hline - $\quad \mathrm{Bad}$ & 6 & 12.0 \\
\hline
\end{tabular}

\begin{tabular}{|c|c|c|}
\hline \multicolumn{3}{|c|}{ Overall satisfaction on emergency unit } \\
\hline - Good & 23 & 46.0 \\
\hline - $\mathrm{Bad}$ & 27 & 54.0 \\
\hline \multicolumn{3}{|c|}{ Comments to improve the emergency unit* } \\
\hline $\begin{array}{l}\text { - trained manpower } \\
\text { should be increased }\end{array}$ & 27 & 40.9 \\
\hline $\begin{array}{l}\text { - supply should be } \\
\text { increased }\end{array}$ & 22 & 33.3 \\
\hline $\begin{array}{l}\text { - need quick } \\
\text { emergency } \\
\text { management }\end{array}$ & 8 & 12.1 \\
\hline $\begin{array}{l}\text { - lab facilities should } \\
\text { be available }\end{array}$ & 9 & 13.6 \\
\hline
\end{tabular}

Table 2 summarized the opinion of respondents on service of emergency unit and their suggestion. Maximum respondents 43(86\%) saw the display board on emergency, $48(96.0 \%)$ respondents attended by HCP immediately. 29(58\%) got drugs from hospital and only $10(20.0 \%)$ got full course of drugs from hospital. Half of the patients $25(50 \%)$ buy drugs from local dispensary, investigation was also done half of the patients. With them only 14(28\%) respondents did their investigation at hospital. After reaching at emergency, maximum patients $25(50 \%)$ waited for 1-5 minutes for receiving medical attention and mean waiting time was 10.14 minutes. Maximum respondents $44(88 \%)$ gave their opinion as good on reception and treatment facilities, service of doctors and others HCPs at emergency unit .Overall satisfactory level at emergency unit, was good 23(46\%) and bad $27(54 \%)$. Comments to improve the service at emergency unit had multiple responses.

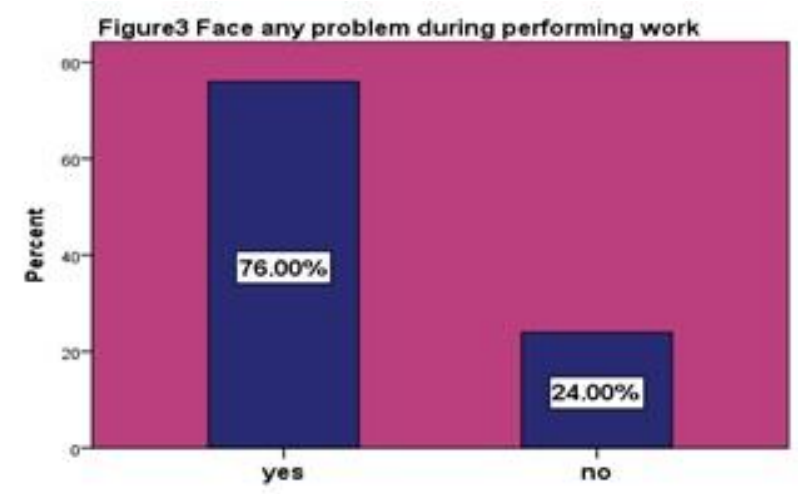

Figure 2 shows that $38(76 \%)$ health care providers face problem during performing duties at emergency unit only $12(24 \%)$ did not face any problem during duty.

Figure 3 Box plot showing patients' waiting time after arrival at emergency department and according 
to receive an emergency service which is normally distributed.

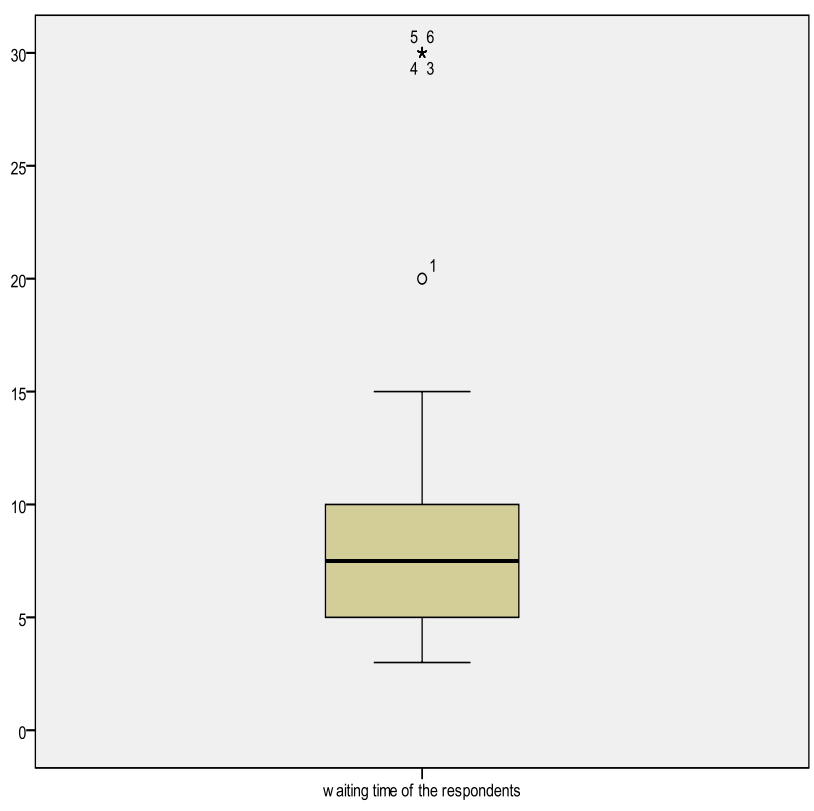

Figure 3: Box plot of waiting time of the patients receiving emergency service

Table 3 summarized the suggestions gave by the health care providers to improve the emergency unit.

Maximum (22 HCP) health care providers gave suggestion to increase trained manpower, $13 \mathrm{HCP}$ suggested to increase the supply of drugs, $6 \mathrm{HCP}$ suggested to need casual OT and $8 \mathrm{HCP}$ suggested to increase security.

Table 3: Suggestion of HCP to improve the service of emergency unit $(n=25)$

\begin{tabular}{|l|c|c|}
\hline \multicolumn{1}{|c|}{ Suggestion of HCP } & Frequency & Percent \\
\hline $\begin{array}{l}\text { Trained Manpower } \\
\text { Should Be Increased }\end{array}$ & 22 & 44.9 \\
\hline $\begin{array}{l}\text { Supply Of Drugs Should } \\
\text { Be Increased }\end{array}$ & 13 & 26.5 \\
\hline $\begin{array}{l}\text { Need Casual OT } \\
\text { Emergency Management }\end{array}$ & 6 & 12.2 \\
\hline Improve Security & 8 & 16.3 \\
\hline Total & 49 & 100.0 \\
\hline
\end{tabular}

*Multiple response analysis

Table 4 summarized that there was a significant difference on waiting time and satisfactory level of patients at emergency unit. At 5\% level of significance $\mathrm{t}=6.516(2$ tailed $)$
Table 4: Relationship between waiting time and satisfactory level of the patients at emergency unit

\begin{tabular}{|l|c|c|c|}
\hline \multirow{2}{*}{$\begin{array}{l}\text { Waiting time of } \\
\text { the respondents }\end{array}$} & \multicolumn{2}{|c|}{$\begin{array}{c}\text { T test for } \\
\text { equality of mean }\end{array}$} & $\begin{array}{l}\text { Sig (2 } \\
\text { tailed) }\end{array}$ \\
\cline { 2 - 3 } & $\mathbf{t}$ & $\mathbf{d f}$ & \\
\hline $\begin{array}{l}\text { Equal variances } \\
\text { not assumed }\end{array}$ & 6.516 & 23.497 & 0.000 \\
\hline
\end{tabular}

\section{Discussion}

Most of the respondents 15(30.0\%) are in 26 to 35 years of age group. According to their education level, 24(48.0\%) respondents are illiterate and can sign only. Most of the respondents (34.0\%) are housewives. Among them maximum (96.0\%) respondents are Muslim. However, 33(66.0\%) respondents are married. Maximum respondents $26(52.0 \%)$ respondents are in 10000 to 15000 tk income group. Male was 26(52\%) and female was $24(48 \%)$ in comparison with a study male $66.4 \%$ over $87.0 \%$ of the respondents were more than 30 years old and $53.55 \%$ were employed while rest were students, housewives or retired. Majority of the respondents (44\%) were illiterate. Most of the respondents were married ${ }^{6}$. In another study it was found that $128(74.4 \%)$ respondents were in more than 10000 taka monthly family income ${ }^{2}$; however, in this study 26(52\%) respondents are between 10000 to 15000 taka group. From a study it was found that, $86.7 \%$ study participants were satisfied by service provided in emergency outpatient department. Male were $66.3 \%$ and female were $33.7 \%$. Maximum patients $(34.4 \%)$ are between 28 to 37 years age group and illiterate 27(6.6\%) respondents ${ }^{4}$. Patients were relatively young with a mean age of 37.19 years. Their family income is 6721.37 taka and chunk of patients involve in small business $(25.3 \%)$ followed by private job $(24.2 \%)$, day labour (15.3\%), housewife (14.7\%) and government employee $(8.4 \%)^{10}$.

In this study, 23(46\%) patients were satisfied to the service of emergency department and others $56.0 \%$ were dissatisfied. From a study of Qadriss et $\mathrm{al}^{6}$ it was found that overall $89.1 \%$ of the patients were satisfied with the services while remaining $10.9 \%$ were dissatisfied. However $20.7 \%$ and $13.0 \%$ of patients were dissatisfied with organization of care and cost of care respectively ${ }^{6}$. Nearly half of the patients $48 \%$ felt that they had to wait too long to get a bed in the hospital after presenting to the emergency unit.68.6\% of the patients said that they were never asked for views on the quality of care 
provided. $20 \%$ of the patients did not find any one in the staff to talk to about their worries and fear ${ }^{2}$.

It was found that, 27(40.9\%) of patients suggested to increase manpower and $22(33.3 \%)$ advised to increase supply of drugs and equipment. Maximum waiting time of the patients $21(42 \%)$ were 5 minutes but the mean was 10.14 minutes. 5 to 10 minutes time was taken to provide a bed after arrival at the emergency department ${ }^{3}$. It was similar with this study. In a study it was shown that mean waiting time was 6.11 minutes, minimum waiting time 1 minute and maximum 16.00 minutes. Availability of trolleys and wheel chair $(80 \%)$ were satisfied and availability of sign boards and way finding were $150(75.0 \%)^{1}$ but in this study $43(86 \%)$ patients saw the display board, $36(76 \%)$ patients attended emergency by walking and other by stretcher or wheel chair.

There are some limitations of this study. This study was carried out only in one tertiary care hospital of Dhaka city and therefore we may not be able to generalize its conclusions to the whole city. Sample size were small .To draw inference large sample size should be needed. It will be more accurate if the sampling will be probability sampling.

Lastly, all questions are subjective in nature and we have not used any objective tool to measure patient satisfaction. This limits our ability to compare our results with studies that use different questionnaires to assess patient satisfaction. Furthermore, we have not attempted to perform a transcultural validation of the translated questionnaire.

\section{Conclusion}

In conclusion overall the study showed a moderate level of satisfaction of patients with services satisfy.
More availability and accessibility obtained from this tertiary care centre. Numbers of potential barriers influence the patients' should be assured. Certain improvements are needed to reduce waiting time. Periodic patient satisfaction survey should be institutionalized to provide feedback for continuous quality improvement.

\section{References}

1. Jalali S, Jan FA, Rashid H, Hamid S, Evaluation of Patient satisfaction in Emergency Department of a tertiary care hospital in North India. Sch J App Med Sci 2016; 4(10B):36343639

2. Imam SZ, Syed KS, Ali SA, Ali SU, Fatima K, Gill M, et al. Patients' satisfaction and opinions of their experiences during admission in a tertiary care hospital in Pakistan - a cross sectional study BMC Health Services Research 2007;7:161

3. Saleem S, Rao AS, Hannan N, Wahid A. The Level of Patient Satisfaction in Emergency Departments of Public Sector Tertiary Care Hospitals, Faisalabad. APMC 2018;12(1):34-9.

4. Worku M, Loha E. Assessment of client satisfaction on emergency department services in Hawassa University Referral Hospital, Hawassa, Southern Ethiopia. BMC Emergency Medicine 2017;17:21

5. Messina G, Vencia F, Mecheroni S, Dionisi S, Baragatti L, Nante N. Factors Affecting Patient Satisfaction With Emergency Department Care: An Italian Rural Hospital, Global Journal of Health Science 2015;7(4):

6. Qadri S S, Pathak R, Singh M, Ahluwalia SK, Saini S, Garg PK, An Assessment of Patients Satisfaction with Services Obtained From a Tertiary Care Hospital in Rural Haryana International Journal of Collaborative Research on Internal Medicine \& Public Health 2012;4(8):1524-1537

7. Aldana J M, Piechulek H, Sabir A A, Client satisfaction and quality of health care in rural Bangladesh Bulletin of the World Health Organization, 2001;79:512-517

8. Annex E. Standardization of Equipment for 500-Bed Tertiary-Level Hospital, Table of Organization and Equipment for 10-, 20-, 50-, 250- And 500-Bed Hospitals in Bangladesh: Standardization Of Medical Equipment, April 2016 Page 35-77 9.https://www.slideshare.net/drdipto2015/satisfactions-amongadmitted-patient-of-tertiary-level-hospital-in-dhaka-city;dated30-6-18

10. Ashrafun L, Uddin M J. Factors Determining Inpatient Satisfaction with Hospital Care in Bangladesh, Asian Social Science, 2011;7(6): 